\title{
A GIBBERELLIN, ABSCISIC ACID, AND DELAY OF GERMINATION 1 INTERACTION NETWORK REGULATES CRITICAL DEVELOPMENTAL TRANSITIONS IN MODEL PLANT ARABIDOPSIS THALIANA - A REVIEW
}

\author{
GUAN, S. X. ${ }^{1,2}-$ LI, Y. S. ${ }^{2}-$ ZENG, W. Q. ${ }^{2}-$ LIN, J. W. ${ }^{3}-$ ZHAN, H. ${ }^{1,2}-$ HAN, X. Y. ${ }^{2}-$ \\ ZHANG, X. L. ${ }^{2}-\mathrm{LU}, \mathrm{X} . \mathrm{J}^{2^{*}}$ \\ ${ }^{1}$ College of Horticulture, Shenyang Agricultural University, Shenyang 110866, Liaoning, China \\ ${ }^{2}$ College of Forestry, Shenyang Agricultural University, Shenyang 110866, Liaoning, China \\ ${ }^{3}$ College of Bioscience and Biotechnology, Shenyang Agricultural University, Shenyang \\ 110866, Liaoning, China \\ *Corresponding author \\ e-mail: lxjsyau@syau.edu.cn
}

(Received 24 $4^{\text {th }}$ Jul 2021; accepted 20 ${ }^{\text {th }}$ Sep 2021)

\begin{abstract}
Seed germination and flowering are two critical developmental transitions in the life cycles of plants. These transitions are coordinately regulated by exogenous environmental cues and endogenous hormonal signals to match plant establishment and reproduction to the appropriate seasons. The phytohormones, abscisic acid (ABA) and gibberellins (GAs), are the key players that antagonistically regulate seed dormancy and germination; ABA positively modulates dormancy induction and maintenance, while GA stimulates germination. For the control of flowering time, GA has been shown to have a positive role in the modulation of floral transition, whereas both positive and negative roles have been recorded for ABA in this process. DELAY OF GERMINATION 1 (DOGl) delays floral transition and functions in dormancy induction and maintenance, acting in parallel with ABA and/or GA. However, DOG1 is also involved in $\mathrm{ABA}$ and $\mathrm{GA}$ antagonism through affecting hormone biosynthesis and/or signal transduction pathways. Moreover, the expression of DOG1 is directly regulated by ABA. In this review, we summarize recent developments in seed dormancy and flowering research on the model plant Arabidopsis thaliana, focusing on the crosstalk between ABA, GA, and DOG1. Finally, the open questions and remaining challenges in this field are presented.
\end{abstract}

Keywords: seed dormancy, flowering, phytohormone, DOG1, crosstalk

\begin{abstract}
Abbreviations: 13ox: GA 13-oxidase, 2ox: GA 2-oxidase, 20ox: GA 20-oxidase, 3ox: GA 3-oxidase, AAO3: abscisic aldehyde oxidase, ABA: abscisic acid, ABA2: ABA deficient 2 (short chain alcohol dehydrogenase), ABI: ABA INSENSITIVE, ABRE: ABA responsive element, AGL24: AGAMOUS LIKE 24, AP1: APETALA1, AREB/ABF: ABRE-binding protein/ABRE-binding factor, BRs: brassinosteroids, CE1: coupling element 1, CHD3: chromodomain-helicase-DNA-binding domain, CO: CONSTANS, CPS: ent-copalyl diphosphate synthase, CTKs: cytokinins, Cvi: Cape Verde Islands, CYP707A: ABA 8'hydroxylase, DOG1: DELAY OF GERMINATION 1, DPA: dihydrophaseic acid, ent-CDP: ent-copalyl diphosphate, ET: ethylene, FLC: FLOWERING LOCUS C, FT: FLOWERING LOCUS T, FUL: FRUITFULL, GAs: gibberellins, GGDP: geranylgeranyl diphosphate, GID1: GIBBERELLIN INSENSITIVE DWARF1, JA: jasmonic acid, KAO: ent-kaurenoic acid oxidase, KO: ent-kaurene oxidase, KS: ent-kaurene synthase, Ler: Landsberg erecta, LFY: LEAFY, miRNAs: microRNAs, NCEDs: 9-cisepoxycarotenoid dioxygenases, NSY: neoxanthin synthase, PA: phaseic acid, PKL: PICKLE, PP2Cs: protein phosphatases type 2C, PRC2: Polycom Repressive Complex 2, PYL: pyrabactin-like, PYR: pyrabactin resistance, RCAR: regulatory components of ABA receptors, RY/Sph: RY/Sph element, SA: salicylic acid, SAM: shoot apical meristem, SCF: Skp1-cullin-F-box, SLs: strigolactones, SMZ: SCHLAFMUTZE, SnRK2s: Snf1-related protein kinases type 2, SNZ: SCHNARCHZAPFEN, SOC1: SUPPRESSOR OF OVEREXPRESSION OF CONSTANS 1, SPL: SQUAMOSA PROMOTER BINDING PROTEIN-LIKE, TOE: TARGET OF EAT, TSF: TWIN SISTER OF FT, Ub: ubiquitin, ZEP: zeaxanthin epoxidase
\end{abstract}




\section{Introduction}

As sessile organisms, plants cannot actively determine where they establish themselves, but they can adapt to environmental changes through several specific mechanisms. Annual plants acclimatize to their environment by precisely matching their life cycles, especially seed germination and flowering, to seasonal conditions (Huo et al., 2016). Seed dormancy, which has been described as 'the incapacity of a viable seed to germinate under favorable conditions', is an important adaptive trait determining plant survival (Bewley, 1997; Finch-Savage and Leubner-Metzger, 2006). Seed dormancy is induced during seed maturation, preventing or delaying germination of maturated seeds until conditions are conducive to the beginning of a new life cycle (Baskin and Baskin, 2004; Bewley et al., 2013). Flowering is another important adaptive trait for plant species and the correct timing of the transition to flowering is pivotal for the reproductive success of all flowering plants as its timing must match the right conditions for fertilization and seed dispersal (Huijser and Schmid, 2011; Yamaguchi and Abe, 2012). Recent studies have suggested that classic genes modulating flowering, such as FLOWERING LOCUS $C(F L C)$ and FLOWERING LOCUS T (FT), also participate in the transition from seed dormancy to germination (Chiang et al., 2009; Chen et al., 2014; Zhao et al., 2015), indicating that seed dormancy and flowering may be coordinately modulated via overlapping molecular pathways (Huo et al., 2016). It is increasingly clear that germination cannot be considered in isolation from flowering since these two processes can have cascading effects on each other (Post et al., 2008; Huo et al., 2016), with consequences for life-cycle expression (Burghardt et al., 2015; Springthorpe and Penfield, 2015) and potentially also for adaptation (Chiang et al., 2013).

Germination and flowering time are triggered and regulated by both exogenous environmental cues and endogenous hormonal signals (Huijser and Schmid, 2011; Conti, 2017; Buijs et al., 2018). The status of germination and flowering depends on the balance between abscisic acid (ABA) and the gibberellins (GAs) (Finkelstein et al., 2008; Holdsworth et al., 2008; Lee et al., 2015; Shu et al., 2017). Abscisic acid is needed for dormancy induction and maintenance (Finch-Savage and Leubner-Metzger, 2006; Finkelstein et al., 2008; North et al., 2010; Dekkers and Bentsink, 2015), whereas GA is required for germination (Karssen and Lacka, 1986; Finch-Savage et al., 2007; Holdsworth et al., 2008; Née et al., 2017b). Gibberellin has a positive effect on floral transition (Ding et al., 2013; Hyun et al., 2016), while both positive and negative effects of ABA on flowering have been reported (Riboni et al., 2013; Wang et al., 2013). DELAY OF GERMINATION 1 (DOGl) delays floral transition and is a crucial player in dormancy induction and maintenance (Nakabayashi et al., 2012; Huo et al., 2016; Li et al., 2019). The DOG1-mediated regulatory pathway is distinct from those of ABA and/or GA (Huo et al., 2016; Shu et al., 2016b). However, DOG1 can carry out functions, central to ABA and GA antagonism, that influence hormone biosynthesis and/or signal transduction pathways (Tuan et al., 2018). Moreover, DOG1 expression is controlled directly by ABA (Graeber et al., 2010, 2013).

In this review, we summarize recent advances, mainly in the case of the model plant Arabidopsis thaliana, associated with the modulation of seed dormancy and flowering, focusing on the three crucial players, ABA, GA, and DOG1. Finally, unanswered questions and future directions for research in this area will be discussed. 


\section{The roles of ABA metabolism and signaling in modulating seed dormancy induction and maintenance}

The phytohormone ABA is a master inducer and protector of seed dormancy (Vaistij et al., 2013), and both ABA content and related sensitivity have been shown to be important for these processes (Bewley et al., 2013; Finkelstein, 2013; Dekkers and Bentsink, 2015). The role of ABA in seed dormancy is conserved among different species (Dekkers and Bentsink, 2015). Evidence for the role of ABA in dormancy is provided by the dormancy variability observed among Arabidopsis seeds with altered ABA biogenesis or signaling genes. Seeds that lose the ability to produce ABA (Frey et al., 2011) or transduce the ABA signal (Ma et al., 2009; Park et al., 2009) have reduced seed dormancy levels. In contrast, seeds that accumulate high ABA levels, or those that possess an ABA hypersensitive phenotype, show increased seed dormancy (Cutler et al., 1996; Matakiadis et al., 2009; Martinez-Andujar et al., 2011; Nonogaki et al., 2014). Similar results were also reported for other species. An increase in ABA content resulted in an enhanced degree of seed dormancy in wheat (Chono et al., 2013). In tomato, defective ABA signaling resulted in nondormant seeds (Groot and Karssen, 1992) whereas higher ABA content increased seed dormancy levels (Thompson et al., 2000). Moreover, active ABA biogenesis is essential for the maintenance of dormancy in imbibed Arabidopsis and Nicotiana plumbaginifolia seeds (Grappin et al., 2000; Ali-Rachedi et al., 2004). Maintenance of seed dormancy is also determined by seed sensitivity to ABA (Tuan et al., 2018). Enhanced ABA sensitivity is necessary to maintain dormancy during imbibition of both wheat and Arabidopsis seeds (Barrero et al., 2010; Tuttle et al., 2015). These studies highlighted the important roles that ABA plays in seed dormancy.

\section{ABA metabolism}

The cellular level of ABA is modulated by its biosynthesis and catabolism (Nambara and Marion-Poll, 2005; Nambara et al., 2010; Tuan et al., 2018) (Fig. 1). Nine-cisepoxycarotenoid dioxygenases (NCEDs) catalyze the cleavage of 9-cis-violaxanthin and 9'-cis-neoxanthin, which is the rate-limiting step in ABA biosynthesis (Schwartz et al., 2003). Abscisic acid is inactivated either by hydroxylation or conjugation with a sugar. The catabolism of ABA occurs primarily through 8 '-hydroxylation via the activity of ABA 8'-hydroxylase (ABA8'OH) (Nambara and Marion-Poll, 2005; Finkelstein, 2013) which is encoded by the CYP707A genes (Kushiro et al., 2004; Saito et al., 2004). All plant species identified to date have NCED and CYP707A as multigene families, indicating that the expression of these factors is important for the regulation of seed ABA levels and, consequently, dormancy and germination.

\section{ABA signaling}

The core ABA signaling pathway contains three master components: pyrabactin resistance (PYR)/pyrabactin-like (PYL)/regulatory components of ABA receptors (RCAR) family members, protein phosphatases type 2C (PP2Cs), and Snf1-related protein kinases type 2 (SnRK2s) (Cutler et al., 2010; Dekkers and Bentsink, 2015; Vishwakarma et al., 2017) (Fig. 2). A recent significant finding was the identification of the ABA receptors PYR/PYL/RCAR that have a major role in seed responsiveness to ABA (Ma et al., 2009; Park et al., 2009). Fourteen members of this protein family (PYR1, PYL1-13) are encoded in the Arabidopsis genome, with the pyrl prll prl2 prl4 quadruple mutant displaying a strong ABA-insensitive germination phenotype (Park et al., 2009). 
Members of the PP2C gene family, including ABA INSENSITIVE 1 (ABI1) and ABI2, are prominent regulators. Mutations in these genes result in ABA hypersensitivity (Koornneef et al., 1984; Gosti et al., 1999), suggesting that they are negative regulators of ABA signaling (Yoshida et al., 2015). A member of SnRK2 is a critical positive regulator of ABA signaling (Yoshida et al., 2015). Three Arabidopsis SnRK2 protein kinases (SnRK2.2, SnRK2.3, and SnRK2.6) have been indicated to function redundantly in ABA signal transduction (Nambara et al., 2010). The triple mutant of these kinases is almost completely insensitive to ABA and germinates precociously under conditions of high humidity (Nakashima et al., 2009). In the absence of ABA, PP2Cs repress SnRK2 activity via dephosphorylation of its kinase activation loop; meanwhile, the ABA receptors PYR/PYL/RCAR form a complex with PP2C, which results in the repression of PP2C phosphatase activity and thereby activating SnRK2 in the presence of ABA (Finkelstein, 2013; Ng et al., 2014; Yang et al., 2017). The targets of active SnRK2 have been shown to be ABRE-binding protein/ABRE-binding factor (AREB/ABF) transcription factors, which induce the onset of $\mathrm{ABA}$-responsive gene transcription $(\mathrm{Ng}$ et al., 2014). Among the AREB/ABF transcription factors, ABI5 (bZIP type) plays an important role in modulating seed ABA-responsive genes (Nambara et al., 2010; Finkelstein, 2013; Yu et al., 2015).

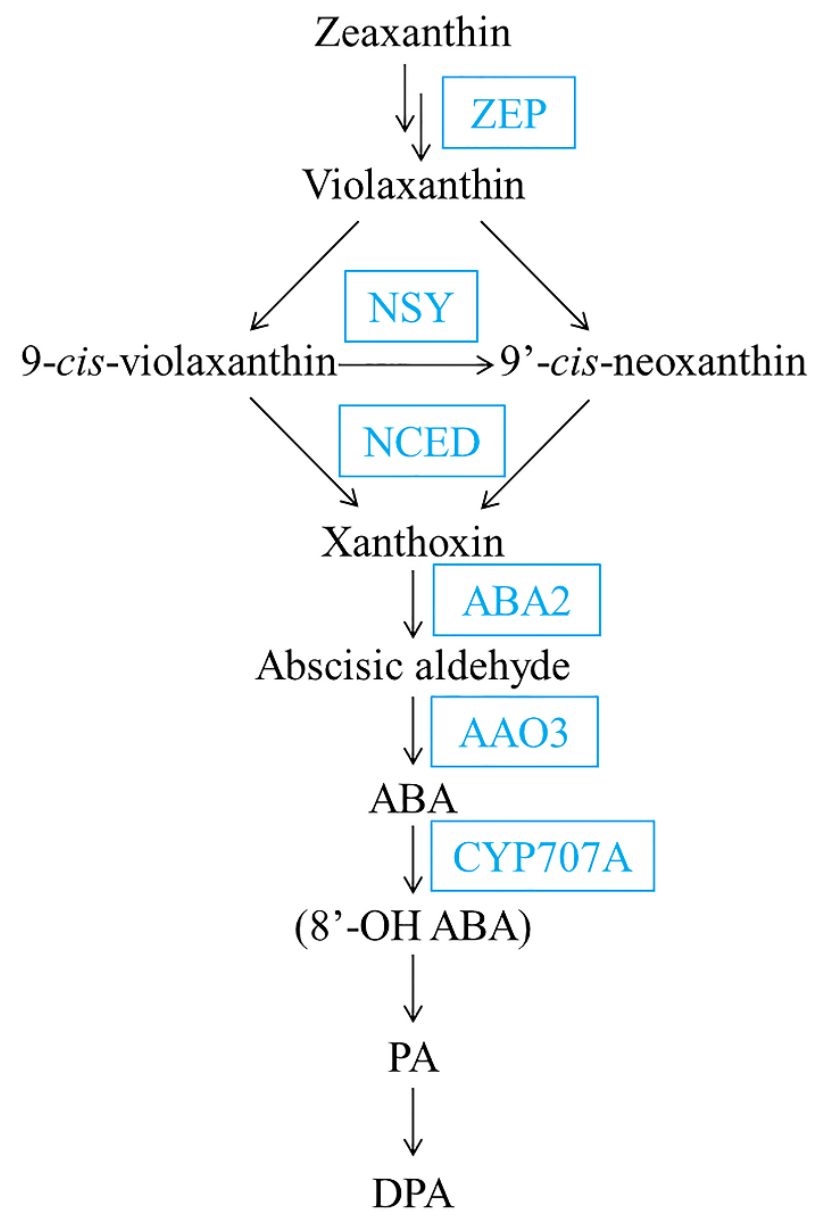

Figure 1. The ABA metabolism pathway. Each box represents an enzyme. ZEP, zeaxanthin epoxidase; NSY, neoxanthin synthase; NCED, 9-cis-epoxycarotenoid dioxygenase; $A B A 2, A B A$ deficient 2 (short chain alcohol dehydrogenase); AAO3, abscisic aldehyde oxidase; CYP707A, ABA 8'-hydroxylase. PA, phaseic acid; DPA, dihydrophaseic acid 


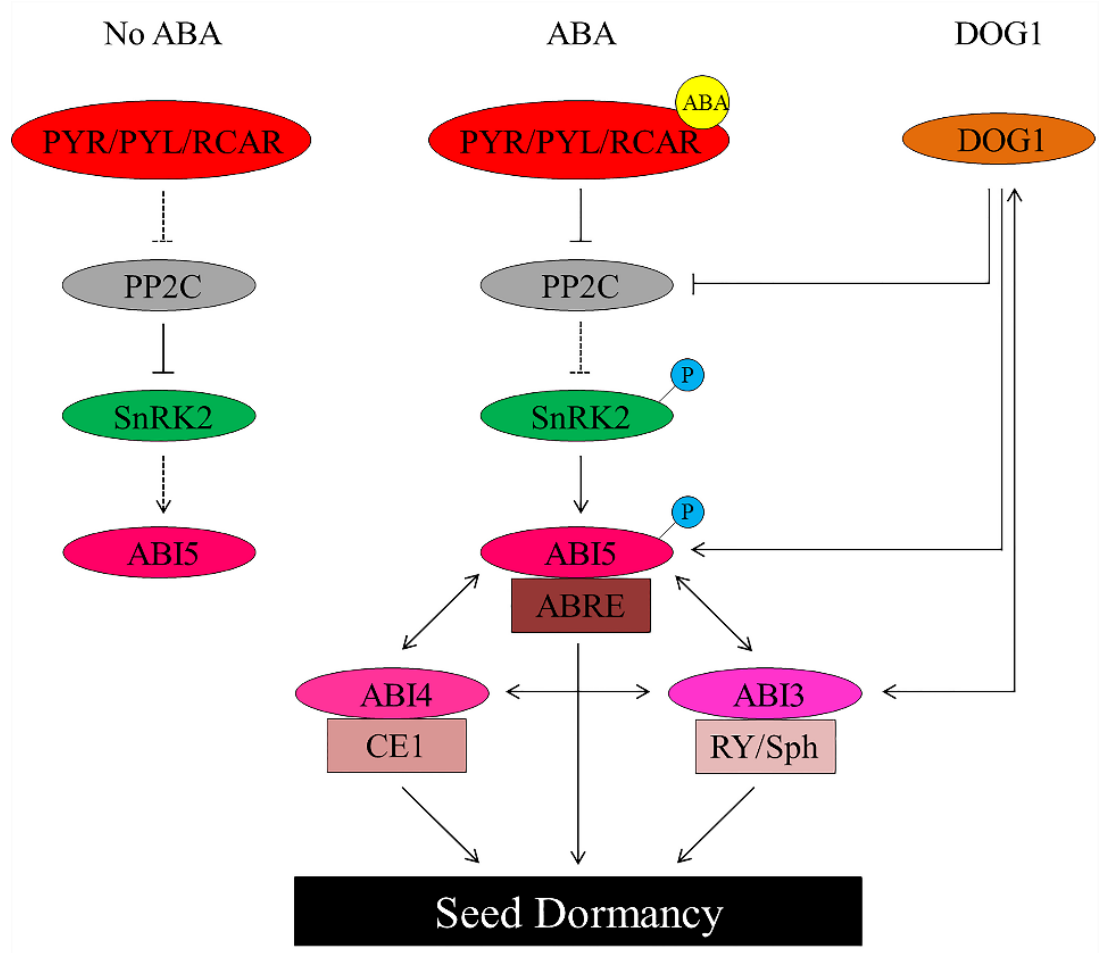

Figure 2. ABA and DOG1 influence seed dormancy via independent pathways. Solid lines denote the valid pathway and dashed lines denote the invalid pathway. Arrows represent positive regulatory role, while bars represent negative regulatory role. $P Y R / P Y L / R C A R$, pyrabactin resistancel/pyrabactin-like/regulatory components of $A B A$ receptors; $P P 2 C$, protein phosphatase 2C; SnRK2, SNF1-related protein kinase 2; ABI3, ABA insensitive 3; ABI4, ABA insensitive 4; $A B I 5, A B A$ insensitive 5. RY/Sph, RY/Sph element; CE1, coupling element 1;

$A B R E, A B A$ responsive element

Transcription is a key step in seed ABA responsiveness. In addition to ABI5, other transcription factor types, including ABI3 (B3 type) and ABI4 (AP2 type), are critical for ABA responsiveness in seeds (Finkelstein et al., 2002; Dekkers and Bentsink, 2015; Shu et al., 2018b). One pioneering study has revealed that abi3, abi4, and abi5 mutants exhibit an ABA-resistant germination phenotype and that these transcription factors seem to interact extensively (Söderman et al., 2000). These transcription factors appear to be conserved among different plant species and corresponding Arabidopsis orthologues are also present in monocots (Nambara et al., 2010). The ABI5/TRAB1, ABI4/ZmABI4 and ABI3/VP1 transcription factors target the ABA-responsive element (ABRE), coupling element 1 (CE1), and RY/Sph repeat element (Nambara et al., 2010), respectively, which act together to activate ABA-mediated transcription and consequently control seed dormancy and germination (Fig. 2).

\section{DOG1 functions independently of $\mathrm{ABA}$ in modulating the induction and maintenance of seed dormancy}

The DOGl gene was first identified as a master quantitative trait locus for seed dormancy using recombinant inbred lines from a cross between the weakly dormant Arabidopsis ecotype Landsberg erecta (Ler) and the strongly dormant Arabidopsis 
ecotype Cvi from the Cape Verde Islands (Alonso-Blanco et al., 2003). Both DOG1 and ABA have been found to modulate dormancy through independent pathways, although they have common downstream targets (Dekkers et al., 2016; Née et al., 2017a; Nishimura et al., 2018) (Fig. 2). In addition, DOG1 can control seed dormancy by an influence on microRNAs (miRNAs) miR156 and miR172 levels (Huo et al., 2016). Like the phytohormone ABA, DOG1 is essential for dormancy induction (Née et al., 2017a; Li et al., 2019); dog 1 mutants are thoroughly nondormant and do not display any obvious pleiotropic phenotypes, except for reduced seed longevity (Bentsink et al., 2006). The effects of a lack of either DOG1 or ABA cannot be rescued by increasing the contents of the other (Nakabayashi et al., 2012). The DOG1 gene encodes a protein lacking domains with any known function and is localized in the nucleus (Bentsink et al., 2006; Nakabayashi et al., 2012; Dekkers and Bentsink, 2015). Importantly, it is expressed only in seeds and its expression increases during seed maturation (Bentsink et al., 2006).

The DOG1 gene is highly conserved in the plant kingdom and homologs in diverse species have been shown to control seed dormancy (Ashikawa et al., 2014; Huo et al., 2016). DOG1 genes have been described in dicots, including Brassica rapa, Lepidium sativum, and Sisymbrium officinale (Graeber et al., 2010, 2014; Carrillo-Barral et al., 2015). Increased DOGl expression was reported for ABA-treated L. sativum seeds, suggesting that DOG1 acts in germination timing in this species (Graeber et al., 2010). In S. officinale, SoDOG1 expression peaked at the onset of silique maturation, identical to that reported for Arabidopsis (Bentsink et al., 2006; Carrillo-Barral et al., 2015). In addition, DOG1-like genes have also been reported in monocots like Oryza sativa, Triticum aestivum, and Hordeum vulgare (Ashikawa et al., 2010; Sugimoto et al., 2010). Overexpression of a wheat DOG1-like gene increases the dormancy level in this species (Ashikawa et al., 2014). Interestingly, ectopic expression of DOGl-like genes from rice, wheat, and barley increases dormancy when expressed in Arabidopsis (Ashikawa et al., 2013). Moreover, high DOG1 transcript levels during maturation may be involved in dormancy maintenance in imbibed S. officinale and Arabidopsis seeds (Nakabayashi et al., 2012; Carrillo-Barral et al., 2015). Hence, like ABA, DOG1 is also a key regulator of seed dormancy.

\section{The roles of GA metabolism and signaling in modulating seed germination}

The GAs stimulate seed germination in numerous plant species. Both GA content and sensitivity to GA are important for seed germination (Karssen and Lacka, 1986; Derkx and Karssen, 1993; Yamaguchi and Kamiya, 2002; Yamauchi et al., 2004; Ariizumi et al., 2013; Tuttle et al., 2015). The GA-deficient Arabidopsis mutant is non-germinating (Koornneef and Van der Veen, 1980). In agreement with this, GA deficiency in tomato results in non-germinating seeds (Koornneef et al., 1990). Semidominant gai mutants exhibit a GA-insensitive phenotype with reduced germination ability in both Arabidopsis (Koornneef et al., 1985; Derkx and Karssen, 1993) and grape (Boss and Thomas, 2002). Furthermore, imbibition leads to increased GA content as well as sensitivity to GA in both Arabidopsis and wheat seeds (Derkx and Karssen, 1993; Izydorczyk et al., 2017), indicating that increased GA content and sensitivity to GA are necessary for promoting seed germination. Therefore, the role of GA in seed germination appears to be conserved among plant species. 


\section{GA metabolism}

Gibberellin is the master plant hormone with a vital role in the regulation of seed dormancy and germination (Finch-Savage and Leubner-Metzger, 2006). The content of bioactive GAs in plant tissues is controlled by the equilibrium between its biosynthesis and inactivation (Yamaguchi, 2008; Tuan et al., 2018). The biosynthesis of GA is modulated primarily via reactions catalyzed by both GA 20-oxidase (GA20ox) and GA 3-oxidase (GA3ox), while GA inactivation is mainly regulated via reactions catalyzed by GA 2-oxidase (GA2ox) (Yamauchi et al., 2004; Yamaguchi, 2006; Tuan et al., 2018) (Fig. 3). All plant species examined to date have GA20ox, GA3ox, and GA2ox as multigene families, indicating that these genes play significant roles in controlling seed GA levels and, consequently, dormancy and germination.

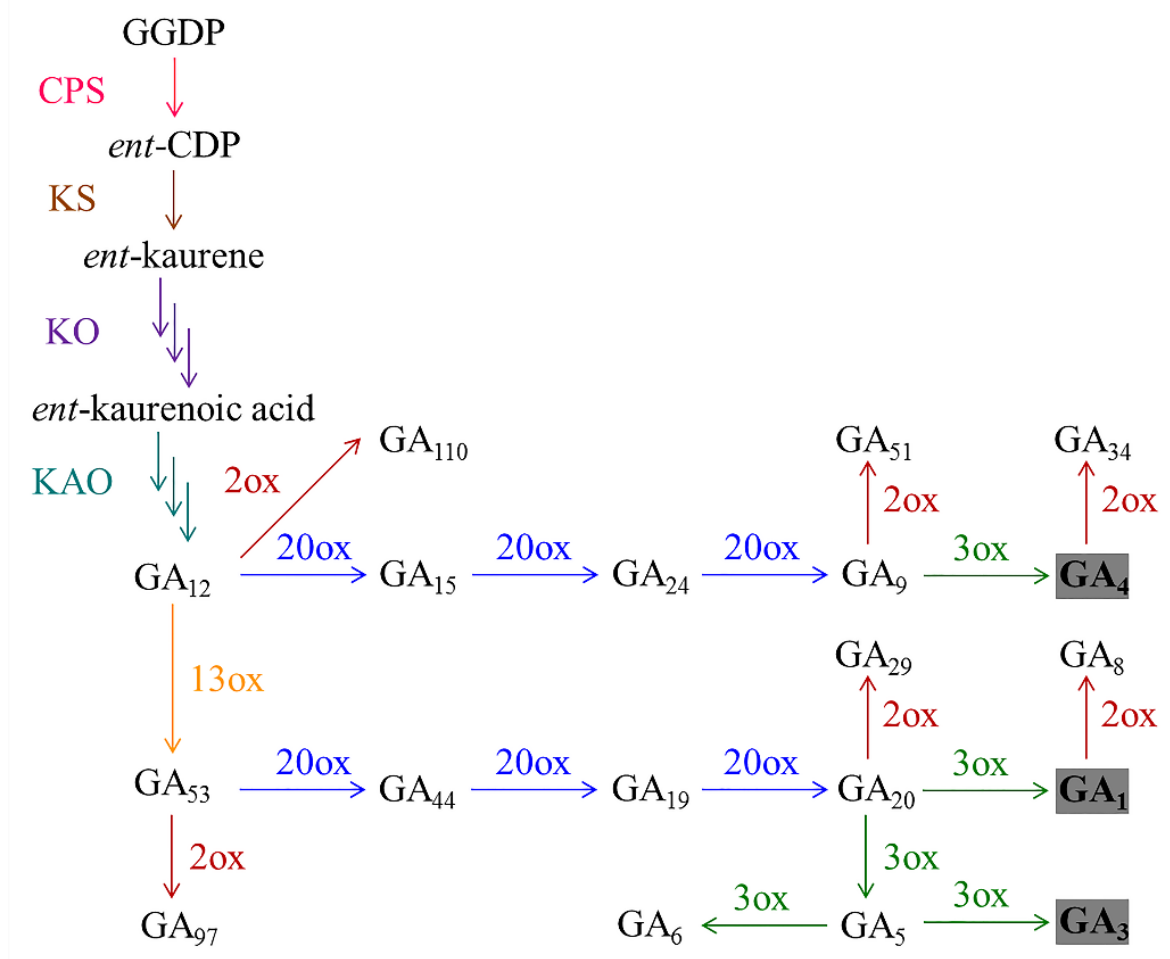

Figure 3. The GA metabolism pathway. Bioactive GAs discovered in various plant species (highlighted dark grey) are exhibited (GA4 is considered to be the major bioactive form in Arabidopsis). GGDP, geranylgeranyl diphosphate; ent-CDP, ent-copalyl diphosphate; CPS, ent-copalyl diphosphate synthase; KS, ent-kaurene synthase; KO, ent-kaurene oxidase; KAO, ent-kaurenoic acid oxidase; 2ox, GA 2-oxidase; 3ox, GA 3-oxidase; 13ox, GA 13-oxidase; 20ox, GA 20-oxidase

\section{GA signaling}

Gibberellin signaling is activated as soon as biologically active GA is perceived via its receptor GIBBERELLIN INSENSITIVE DWARF1 (GID1) (Nakajima et al., 2006) (Fig. 4). The GID1 receptor is triggered upon GA binding, permitting recognition of DELLA proteins. Responses to GA, including induction of seed germination, require GAinduced degradation of DELLA proteins, which function as negative GA signaling regulators (Salazar-Cerezo et al., 2018). Binding of GA to GID1 stimulates GA-GID1- 
DELLA complex formation (Murase et al., 2008), after which the complex is targeted for polyubiquitination through the F-box component of a Skp1-cullin-F-box (SCF) ubiquitin ligase, followed by DELLA degradation via the 26S proteasome (Dill et al., 2004; Fleet and Sun, 2005; Harberd et al., 2009; Gao et al., 2011; Wallner et al., 2016).

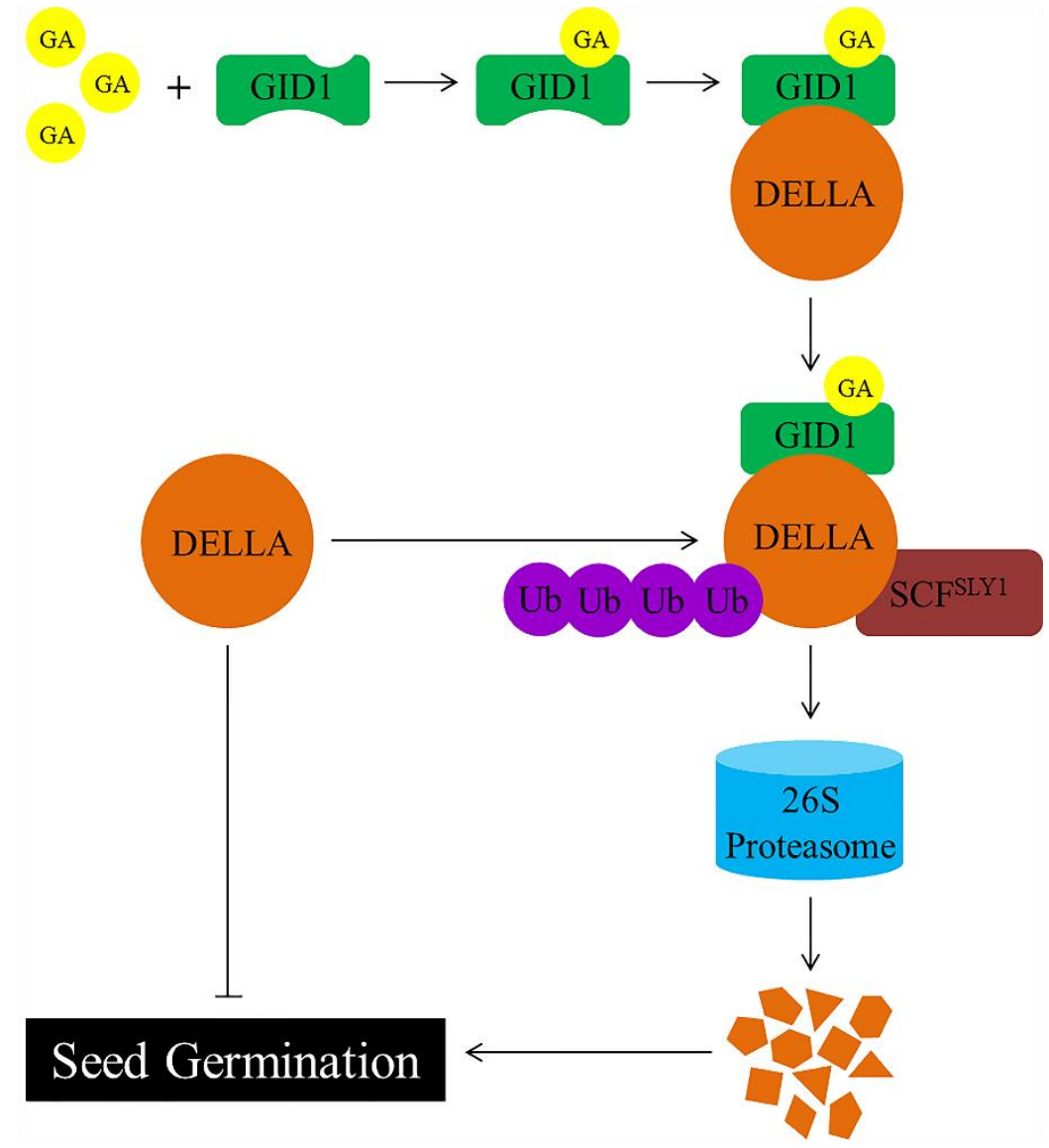

Figure 4. The GA signaling pathway. A relief of inhibition induces seed germination. DELLA protein will be polyubiquitinated and then degraded through the ubiquitin-proteasome pathway.

The arrows and bars denote the positive and negative regulation, respectively. GID1, gibberellin insensitive dwarf1; SCF(SLY1), Skp1-cullin-F-box; Ub, ubiquitin

\section{GA, ABA, and DOG1: focusing on the regulation of flowering time}

Accurate time of flowering is pivotal and significant for the growth and survival of plants under various environmental conditions. ABA has been implicated in the control of flowering time (Riboni et al., 2013; Wang et al., 2013). Nevertheless, the contribution of ABA to the regulation of flowering time remains controversial since both positive and negative effects have been documented (Riboni et al., 2016; Shu et al., 2016a). ABA acts as a positive regulator of flowering by activating FT and TWIN SISTER OF FT (TSF) genes during long days (Riboni et al., 2013, 2016). Mutants of $A B A 1$ or $A B A 2$ are deficient in ABA production and either do not flower under short days, or display a late flowering phenotype under long days (Riboni et al., 2013, 2016). ABA promotes floral transition upstream of the CONSTANS (CO) transcriptional activation (Koops et al., 2011; Yoshida et al., 2014; Riboni et al., 2016). The ABA-mediated $F T$ activation requires CO and repressing ABA signaling remarkably reduces $F T$ expression with little impact on the 
accumulation of $C O$ transcript (Riboni et al., 2016). ABA signaling thus influences $C O$ activity and/or function rather than its transcript level (Riboni et al., 2016). ABI3 may have an effect on the expression of $F T$ by inhibiting the $\mathrm{CO}$ activity via binding to the CCT domain (Kurup et al., 2000; Zhang et al., 2005). ABA negatively modulates ABI3 through causing the ubiquitination and consequent proteasome-dependent degradation (Zhang et al., 2005). It is likely that ABA might promote the accumulation of $F T$ via CO, partly by the degradation of ABI3 (Conti, 2017). Interestingly, it is also found that the physical interaction between $\mathrm{ABI} 3$ and $\mathrm{CO}$ might enhance the $\mathrm{CO}$ function, and further facilitate $F T$ upregulation (Tiwari et al., 2010). ABA positively regulates $A B I 3$ by promoting its transcription (Finkelstein, 2013). These results demonstrate that ABA might trigger $\mathrm{ABI} 3$ accumulation, and thereby stimulate $F T$ expression by $\mathrm{CO}$. The precise mechanism underlying the role of $\mathrm{ABI} 3$ in regulation of $\mathrm{CO}$ activity in the leaf warrants further exploration.

On the other hand, ABA is also implicated in modulating floral transition downstream of $F T$, but through a negative way. In coincidence with this, loss of function mutants of positive modulators for ABA signaling pathway, abi3, abi4 and abi5, facilitate the floral transition, while overexpressing transgenic plants carrying these genes $(A B I 3, A B I 4$ and $A B I 5$ ) exhibit late flowering phenotypes (Kurup et al., 2000; Zhang et al., 2005; Foyer et al., 2012; Wang et al., 2013; Shu et al., 2016a). These phenotypes may possibly result from a different action mode of ABA in the shoot apical meristem (SAM). It is suggested that the negative effect of ABA on floral transition is played by SUPPRESSOR OF OVEREXPRESSION OF CONSTANS 1 (SOC1) (Riboni et al., 2016). Numerous studies show that ABA directly activates $F L C$ by $A B I 3, A B I 4$ and $A B I 5$ (Wang et al., 2013; Shu et al., 2016a, 2018a). Consequently, ABA might reduce the SOC1 levels through activating $F L C$, leading to a delay in flowering. It is $A B I 4$ and perhaps $A B I 3$ that might contribute to the modulation of $F L C$ and $S O C 1$ during short days for $A B I 5$ does not play a role in floral transition during these conditions (Wang et al., 2013; Shu et al., 2016a, 2018a). Shu et al. (2018a) have proposed a working model for the effect of ABA on flowering. A moderate level of environmental stress (e.g., moderate drought), resulting in ABA accumulation, delays flowering until the stress abates, while a serious level of environmental stress (e.g., serious drought), eliciting marked ABA accumulation, stimulates floral transition to maximize reproductive success. Endogenous ABA accumulation (e.g., through transgene expression) also delayed flowering (Shu et al., 2018a).

The DOG1 gene has been found to influence both germination and flowering time (Chiang et al., 2013; Huo et al., 2016). In Arabidopsis dogl-3 mutants, there are no effects on flowering times under short- or long-day conditions (Huo et al., 2016). In contrast, suppression of expression of DOGl leads to early flowering in lettuce (Huo et al., 2016), as also occurs in wheat (Ashikawa et al., 2014). DOG1 delays flowering time through indirectly inhibiting expression of $F T$ in leaves and of $S O C l$ in apical meristems (Huijser and Schmid, 2011; Spanudakis and Jackson, 2014; Huo et al., 2016). Recent studies delineate a regulatory mechanism between DOG1 and ABA in the context of seed dormancy. DOG1 increases ABA signaling possibly through modulating the transcription of $A B I 5$ and binding to ABI3 (Dekkers et al., 2016). It is obscure whether this pathway also operates in the SAM, and contributes to transcriptional inhibition of SOC1 via FLC activation.

Gibberellin can regulate plant flowering time (Zhu et al., 2016; Gong et al., 2017; Shu et al., 2018b) and the positive effect of GA on floral transition has been extensively 
investigated and documented (Srikanth and Schmid, 2011; Ding et al., 2013; Hyun et al., 2016; Brambilla et al., 2017; Conti, 2017; Sawettalake et al., 2017). The lack of activity of any of the GA biosynthesis and signaling components can elicit defects in flowering (Wilson et al., 1992; Sun and Kamiya, 1994; Iuchi et al., 2007). Mutants defective in GA biosynthesis ( $\mathrm{gal}$ ) display a moderate delay in flowering time during long days but never flower during short day conditions (Wilson et al., 1992). In agreement with the role of GA signaling in flowering, mutants impaired in GA perception (gidl), DELLA ubiquitination (slyl), or mutants with a dominant, non-degradable DELLA protein GAI (gai) show similar flowering phenotypes to the above-mentioned gal biosynthetic mutants (Griffiths et al., 2006; Willige et al., 2007; Galvão et al., 2012; Porri et al., 2012). Conversely, mutants with loss of function alleles in DELLA genes, show early flowering phenotypes (Galvão et al., 2012). Increasing levels of GA facilitate DELLA degradation (Harberd, 2003; Fu et al., 2004), while reduced GA levels increase DELLA accumulation (King et al., 2001; Silverstone et al., 2001). DELLA proteins interact with FLC, which inhibits floral transition by directly repressing the transcriptional activation of floral genes FT and SOC1 in the leaf and SAM, respectively (Li et al., 2016; Conti, 2017). In Arabidopsis, PICKLE (PKL) codes for an ATP-dependent chromodomain-helicaseDNA-binding domain (CHD3) chromatin remodeling enzyme (Zhang et al., 2008). PKL is essential for GA-promoted floral transition and plays a positive role in modulating GA signaling (Park et al., 2017). PKL recruits the Polycom Repressive Complex 2 (PRC2), which elevates histone mark H3K27me3 levels in FLC, thus contributing to the expression of FT and SOC1 (Campos-Rivero et al., 2017). Floral transition is inhibited via DELLA and activated via PKL (Park et al., 2017). PKL is still needed to facilitate flowering in the lack of any functional DELLA (Park et al., 2017). Furthermore, DELLA opposes PKL function through direct protein-protein interaction (Zhang et al., 2014). Nevertheless, further studies are required to elucidate the detailed molecular mechanisms by which ABA, GA, and DOG1 modulate floral transition.

\section{An interaction web consisting of GA, ABA, and DOG1 is implicated in the control of seed dormancy and flowering time}

Recent studies have indicated that DOG1 stimulates the conversion of MIR156 and MIR172 transcripts to miR156 and miR172 through DOG1-stimulated expression of DICER complex components (Huo et al., 2016). miR156 binds specifically to SQUAMOSA PROMOTER BINDING PROTEIN-LIKE (SPL) transcripts and elicits their degradation, which delays or inhibits flowering (Huijser and Schmid, 2011; Spanudakis and Jackson, 2014). SPL3/4/5/9/15 have been shown to target and induce FT expression in leaves and SOC1, AGAMOUS LIKE 24 (AGL24), FRUITFULL (FUL), LEAFY (LFY), and APETALA1 (AP1) expression in apical meristems (Huijser and Schmid, 2011; Spanudakis and Jackson, 2014). SPL9/10/15 can increase miR172 levels by stimulating MIR172 expression (Wang et al., 2009; Wu et al., 2009). miR172 promotes floral transition by inhibiting $A P 2$-like floral repressor genes including $A P 2, T A R G E T$ OF EAT1 (TOE1), TOE2, TOE3, SCHLAFMUTZE (SMZ), and SCHNARCHZAPFEN (SNZ) (Wu et al., 2009; Zhu and Helliwell, 2011) and can also stimulate seed germination (Huo et al., 2016). However, how miR172 achieves this regulatory role is still unclear.

The role of DOG1 in dormancy maintenance was found to be partially mediated via the regulation of GA metabolism through temperature-dependent changes in the expression of GA biosynthetic and inactivation genes (Kendall et al., 2011; Graeber et 
al., 2014). The lower levels of FT and TSF in gidlagid1bgidlc triple mutants conferred a late-flowering phenotype in long days (Galvão et al., 2012). The decreased FT and TSF expression results from the inhibition of SPL3 expression by DELLA proteins in leaves and SPL3, SPL4, and SPL5 in the shoot apex (Galvão et al., 2012; Yu et al., 2012). The DOG1 content is positively correlated with the degree of seed dormancy partly due to the effect of DOG1 on ABA levels in the maturation stage (Chiang et al., 2011; Nakabayashi et al., 2012). In addition, DOG1 expression is directly modulated by ABA (Graeber et al., 2010, 2013). Several studies have demonstrated that DOG1 enhances ABA signaling and, consequently, seed dormancy, through its interaction with PP2C (Née et al., 2017a; Nishimura et al., 2018) and likely also by regulating $A B I 5$ expression and genetically interacting with $A B I 3$ (Dekkers et al., 2016); this suggests that the role of DOG1 in modulating seed dormancy is coordinated with ABA (Nakabayashi et al., 2012). Both ABI4 and ABI5 negatively modulate floral transition by directly promoting FLC transcription (Wang et al., 2013; Shu et al., 2016a), while FLC further inhibits the expression of the florigen gene, $F T$ (Shu et al., 2018a). In addition, ABI4 negatively regulates GA biogenesis, which represses the floral transition (Blazquez et al., 1998; Achard et al., 2004; Shu et al., 2013). Similarly, both ABI5-GA-flowering and ABI3FLC-FT-flowering cascades are proposed (Shu et al., 2018a). Furthermore, the ABI3GA-flowering cascade is valuable hypothesis to identify (Fig. 5).

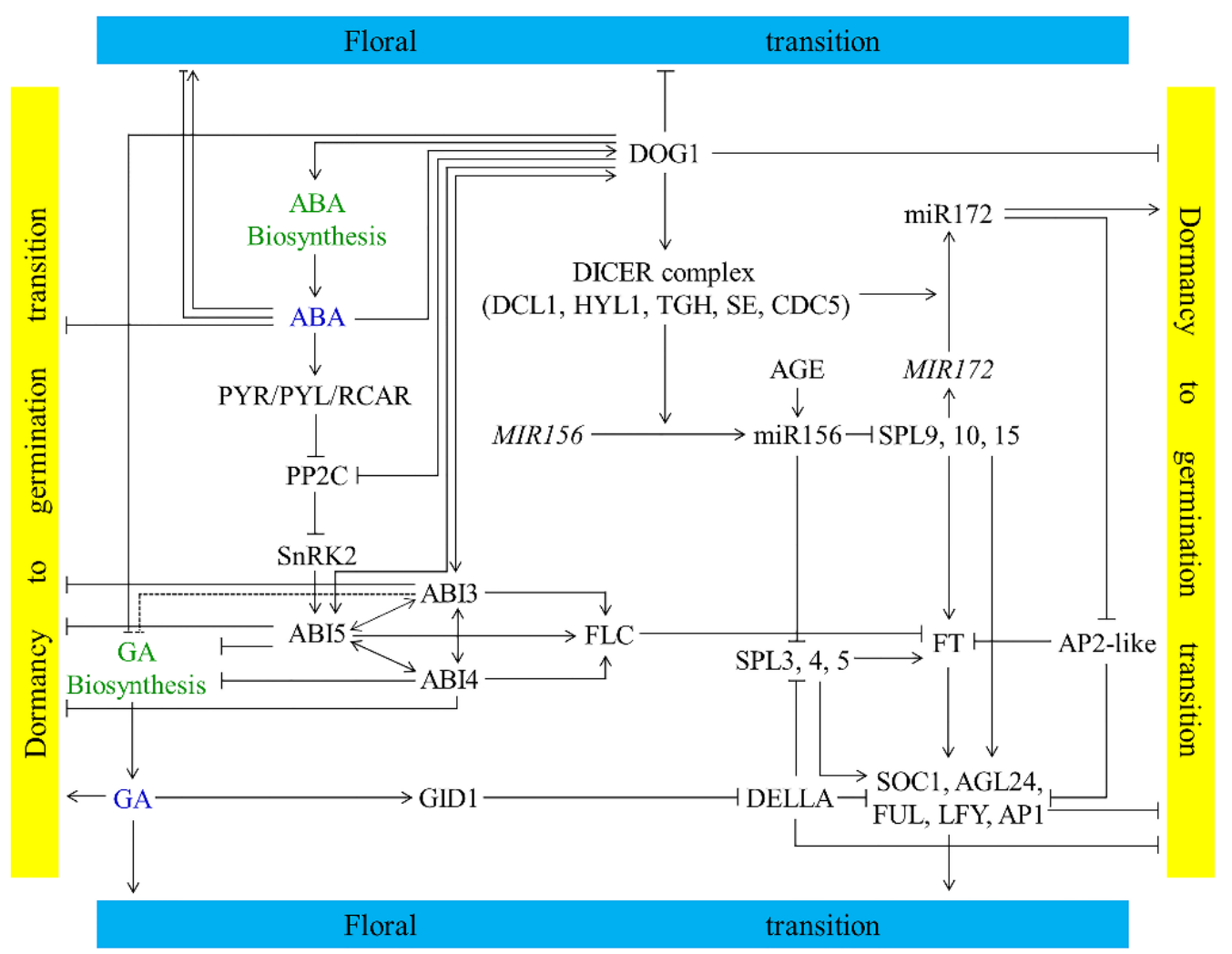

Figure 5. Underlying interactions between GA, ABA and DOG1 in the control of seed dormancy and flowering time. Seed dormancy and flowering are strongly regulated by the content and signaling balance between ABA and GA. DOG1 impinges on this balance and functions in largely parallel to it, and common downstream targets exist between both pathways. ABA in turn directly promotes the expression of DOG1. Solid lines indicate the documented pathway, while dashed lines are proposed from current studies and require further exploration. Arrows represent positive regulation and bars represent negative regulation 
In the flowering pathway, FLC inhibits the genes $F T$ and $S O C 1$, eliciting low API level and thereby impeding flowering (Chiang et al., 2009). The master flowering time gene FLC stimulates seed germination as well (Blair et al., 2017; Auge et al., 2018). Shared pathways of germination and flowering emerge, with $F L C$-mediated germination acting by $F T, S O C 1$, and $A P 1$, similar to what emerges in $F L C$-mediation of flowering (Chiang et al., 2009). FLC modulation of germination subsequently acts by the pathway of ABA catabolism (via CYP707A2) and GA anabolism (via GA20oxl) in germinating seeds (Chiang et al., 2009). Vital components in the same pathway are shared between germination and flowering modulation, but downstream difference may arise. More research on the shared pathways between germination and flowering is clearly required.

In summary, pleiotropy exists in the regulation of germination and flowering. Three important integrators for the modulation of floral transition, FLC, FT, and SOC1, also influence seed germination (Chiang et al., 2009; Chen et al., 2014; Blair et al., 2017). Hence, the three integrators are versatile genes that regulate both seed germination and floral transition. An interaction network consisting of ABA, GA, and DOG1 regulates the transition from seed dormancy to germination. In addition, the ABA, GA, and DOG1 interaction network further extends and converges on the FLC, FT, and SOC1 integrator genes, which confers the function for the regulation of floral transition and seed germination. The three integrator genes are essential for the interaction network in the control of flowering and germination. Consequently, the ABA, GA, and DOG1 interaction network regulates not only floral transition but also the transition from seed dormancy to germination.

\section{The influence of the environment on seed dormancy and flowering}

Various environmental cues determine the proper timing for germination and flowering. Temperature is a particularly important environmental factor influencing seed dormancy. Low temperatures during seed maturation increase seed dormancy levels by increasing the expression of the ABA anabolic gene, NCED4, as well as the expression of GA2ox6, a GA catabolic gene (Kendall et al., 2011). The expression of DOG1 is elevated and dormancy levels are enhanced under low temperatures during seed maturation (Chiang et al., 2011; Nakabayashi et al., 2012; Née et al., 2017b). Seed dormancy increases during the winter as soil temperature declines, while the expression of the DOG1, NCED6 (ABA synthesis), and GA2ox2 (GA catabolism) genes increases (Footitt et al., 2011). Thus, temperature affects seed dormancy both during seed maturation and in the soil via regulation of the ABA, GA, and DOG1 interaction network.

Light is another environmental factor that positively affects seed germination, inducing increased transcription of the GA biosynthetic genes, GA3oxl and GA3ox2, and enhancing the transcription of CYP707A2, an ABA catabolism gene (Cho et al., 2012). Previous studies have shown that blue light inhibits seed germination by promoting the expression of ABA synthesis genes and downregulating the transcription of GA anabolic genes (Gubler et al., 2008; Barrero et al., 2014). Red light and far-red light both control seed germination through changes in the levels of ABA and GA (Seo et al., 2006, 2009). Together, these observations imply that light affects seed germination at least partly by regulating the balance between $\mathrm{ABA}$ and GA. Whether light also influences DOG1 expression and thereby seed germination is a worthwhile project for future investigation.

Temperature and light can also affect flowering time (Srikanth and Schmid, 2011; Cho et al., 2017). This poses the interesting question as to whether the same regulators control 
the ABA, GA, and DOG1 interaction network to modulate seed dormancy and flowering when temperature and light function as environmental factors.

\section{Conclusion and outlook}

The crosstalk between ABA, GA, and DOG1 in the regulation of seed dormancy and flowering is an interesting research area in plant molecular biology. Great advances have been made in our understanding of the molecular mechanisms involved in these processes using the model plant Arabidopsis thaliana. However, several open questions remain to be addressed.

First, plant hormones, including ethylene (ET), brassinosteroids (BRs), jasmonic acid (JA), salicylic acid (SA), cytokinins (CTKs), and strigolactones (SLs), modulate seed dormancy and flowering, most likely by regulating the balance between ABA and GA. Nevertheless, the underlying mechanisms involved in this hormonal balance remain largely unclear. Consequently, it would be worthwhile to establish a metabolic and signaling network for these phytohormones to further elucidate the mechanisms regulating the ABA/GA balance as well as the crosstalk between ABA, GA, and DOG1.

Second, it is necessary to obtain temporal and spatial expression information for the distinct parameters and factors that regulate seed dormancy and/or flowering through their effects on the interaction between ABA, GA, and DOG1, as only this type of information can be used to model the regulation of seed dormancy and/or flowering. However, we still know little about these parameters or the expression pattern of these factors, including those of NCED, CYP707A, GA20ox, GA3ox, GA2ox, DOG1, ABI, FLC, FT, SOC1, and AP1 (Figs. 1, 3 and 5), that act as the central components in the interaction between ABA, GA, and DOG1 and have a crucial function in seed germination and/or flowering.

Third, although ABA has been indicated to control floral transition in both a positive and negative manner, the detailed mechanisms involved, particularly the distinction at the origin of ABA increases caused by moderate or serious environmental stresses and genetic changes, require further study. In addition, ABA and GA act synergistically to positively modulate flowering when ABA plays a positive role in floral transition. However, understanding of the crosstalk between ABA, GA, and DOG1 under this condition is also largely elusive.

Finally, the genes implicated in other phase transitions may also be involved in controlling the transition from dormancy to germination, and genes acting at the seed stage can also regulate subsequent life stages. Consequently, it is possible that the pathway involved in the transition from dormancy to germination is shared with other phase transitions. The identification of a common regulatory web based on ABA, GA, and DOG1 would be a very worthwhile project. Altogether, these remaining scientific questions associated with ABA, GA, and DOG1 are worthy of further investigation.

Acknowledgements. This work was supported by the funding from National Natural Science Foundation of China (No. 31971647 and 31570621). We are grateful to Zhifu Guo and members of our lab for valuable discussion about, and anonymous reviewers for highly constructive comments on, the manuscript. 


\section{REFERENCES}

[1] Achard, P., Herr, A., Baulcombe, D. C., Harberd, N. P. (2004): Modulation of floral development by a gibberellin-regulated microRNA. - Development 131: 3357-3365.

[2] Ali-Rachedi, S., Bouinot, D., Wagner, M. H., Bonnet, M., Sotta, B., Grappin, P., Jullien, M. (2004): Changes in endogenous abscisic acid levels during dormancy release and maintenance of mature seeds: Studies with the Cape Verde Islands ecotype, the dormant model of Arabidopsis thaliana. - Planta 219: 479-488.

[3] Alonso-Blanco, C., Bentsink, L., Hanhart, C. J., Blankestijn-de Vries, H., Koornneef, M. (2003): Analysis of natural allelic variation at seed dormancy loci of Arabidopsis thaliana. - Genetics 164: 711-729.

[4] Ariizumi, T., Hauvermale, A. L., Nelson, S. K., Hanada, A., Yamaguchi, S., Steber, C. M. (2013): Lifting DELLA repression of Arabidopsis seed germination by nonproteolytic gibberellin signalling. - Plant Physiol. 162: 2125-2139.

[5] Ashikawa, I., Abe, F., Nakamura, S. (2010): Ectopic expression of wheat and barley DOG1-like genes promotes seed dormancy in Arabidopsis. - Plant Sci. 179: 536-542.

[6] Ashikawa, I., Abe, F., Nakamura, S. (2013): DOG1-like genes in cereals: investigation of their function by means of ectopic expression in Arabidopsis. - Plant Sci. 208: 1-9.

[7] Ashikawa, I., Mori, M., Nakamura, S., Abe, F. (2014): A transgenic approach to controlling wheat seed dormancy level by using Triticeae DOG1-like genes. - Transgenic Res. 23: 621-629.

[8] Auge, G. A., Blair, L. K., Karediya, A., Donohue, K. (2018): The autonomous floweringtime pathway pleiotropically regulates seed germination in Arabidopsis thaliana. - Ann. Bot. 121: 183-191.

[9] Barrero, J. M., Millar, A. A., Griffiths, J., Czechowski, T., Scheible, W. R., Udvardi, M., Reid, J. B., Ross, J. J., Jacobsen, J. V., Gubler, F. (2010): Gene expression profiling identifies two regulatory genes controlling dormancy and ABA sensitivity in Arabidopsis seeds. - Plant J. 61: 611-622.

[10] Barrero, J. M., Downie, A. B., Xu, Q., Gubler, F. (2014): A role for barley CRYPTOCHROME1 in light regulation of grain dormancy and germination. - Plant Cell 26: 1094-1104.

[11] Baskin, J. M., Baskin, C. C. (2004): A classifcation system for seed dormancy. - Seed Sci. Res. 14: 1-16.

[12] Bentsink, L., Jowett, J., Hanhart, C. J., Koornneef, M. (2006): Cloning of DOG1, a quantitative trait locus controlling seed dormancy in Arabidopsis. - Proc. Natl. Acad. Sci. USA 103: 17042-17047.

[13] Bewley, J. D. (1997): Seed germination and dormancy. - Plant Cell 9: 1055-1066.

[14] Bewley, J. D., Bradford, K. J., Hilhorst, H. W., Nonogaki, H. (2013): Seeds: Physiology of development, germination and dormancy. $-3^{\text {rd }}$ ed., Springer, New York.

[15] Blair, L., Auge, G., Donohue, K. (2017): Effect of FLOWERING LOCUS C on seed germination depends on dormancy. - Funct. Plant Biol. 44: 493-506.

[16] Blazquez, M. A., Green, R., Nilsson, O., Sussman, M. R., Weigel, D. (1998): Gibberellins promote flowering of Arabidopsis by activating the LEAFY promoter. - Plant Cell 10: 791800.

[17] Boss, P. K., Thomas, M. R. (2002): Association of dwarfism and floral induction with a grape 'green revolution' mutation. - Nature 416: 847-850.

[18] Brambilla, V., Gomez-Ariza, J., Cerise, M., Fornara, F. (2017): The importance of being on time: regulatory networks controlling photoperiodic flowering in cereals. - Front. Plant Sci. 8: 665.

[19] Buijs, G., Kodde, J., Groot, S. P., Bentsink, L. (2018): Seed dormancy release accelerated by elevated partial pressure of oxygen is associated with DOG loci. - J. Exp. Bot. 69: 36013608 . 
[20] Burghardt, L. T., Metcalf, C. J., Wilczek, A. M., Schmitt, J., Donohue, K. (2015): Modeling the influence of genetic and environmental variation on the expression of plant life cycles across landscapes. - Am. Nat. 185: 212-227.

[21] Campos-Rivero, G., Osorio-Montalvo, P., Sánchez-Borges, R., Us-Camas, R., Duarte-Aké, F., De-la-Peña, C. (2017): Plant hormone signaling in flowering: An epigenetic point of view. - J. Plant Physiol. 214: 16-27.

[22] Carrillo-Barral, N., Matilla, A. J., García-Ramas, C., Rodríguez-Gacio Mdel, C. (2015): ABA-stimulated SoDOG1 expression is after-ripening inhibited during early imbibition of germinating Sisymbrium officinale seeds. - Physiol. Plant. 155: 457-471.

[23] Chen, M., MacGregor, D. R., Dave, A., Florance, H., Moore, K., Paszkiewicz, K., Smirnoff, N., Graham, I. A., Penfield, S. (2014): Maternal temperature history activates Flowering Locus $\mathrm{T}$ in fruits to control progeny dormancy according to time of year. - Proc. Natl. Acad. Sci. USA 111: 18787-18792.

[24] Chiang, G. C., Barua, D., Kramer, E. M., Amasino, R. M., Donohue, K. (2009): Major flowering time gene, FLOWERING LOCUS C, regulates seed germination in Arabidopsis thaliana. - Proc. Natl. Acad. Sci. USA 106: 11661-11666.

[25] Chiang, G. C., Bartsch, M., Barua, D., Nakabayashi, K., Debieu, M., Kronholm, I., Koornneef, M., Soppe, W. J., Donohue, K., De Meaux, J. (2011): DOG1 expression is predicted by the seed-maturation environment and contributes to geographical variation in germination in Arabidopsis thaliana. - Mol. Ecol. 20: 3336-3349.

[26] Chiang, G. C., Barua, D., Dittmar, E., Kramer, E. M., de Casas, R. R., Donohue, K. (2013): Pleiotropy in the wild: the dormancy gene DOG1 exerts cascading control on life cycles. Evolution 67: 883-893.

[27] Cho, J. N., Ryu, J. Y., Jeong, Y. M., Park, J., Song, J. J., Amasino, R. M., Noh, B., Noh, Y. S. (2012): Control of seed germination by lightinduced histone arginine demethylation activity. - Dev. Cell 22: 736-748.

[28] Cho, L. H., Yoon, J., An, G. (2017): The control of flowering time by environmental factors. - Plant J. 90: 708-719.

[29] Chono, M., Matsunaka, H., Seki, M., Fujita, M., Kiribuchi-Otobe, C., Oda, S., Kojima, H., Kobayashi, D., Kawakami, N. (2013): Isolation of a wheat (Triticum aestivum L.) mutant in ABA 8'-hydroxylase gene: effect of reduced ABA catabolism on germination inhibition under field condition. - Breed. Sci. 63: 104-115.

[30] Conti, L. (2017): Hormonal control of the floral transition: can one catch them all. - Dev. Biol. 430: 288-301.

[31] Cutler, S., Ghassemian, M., Bonetta, D., Cooney, S., McCourt, P. (1996): A protein farnesyl transferase involved in abscisic acid signal transduction in Arabidopsis. - Science 273: $1239-1241$.

[32] Cutler, S. R., Rodriguez, P. L., Finkelstein, R. R., Abrams, S. R. (2010): Abscisic acid: emergence of a core signaling network. - Annu. Rev. Plant Biol. 61: 651-679.

[33] Dekkers, B. J., Bentsink, L. (2015): Regulation of seed dormancy by abscisic acid and DELAY OF GERMINATION 1. - Seed Sci. Res. 25: 82-98.

[34] Dekkers, B. J., He, H., Hanson, J., Willems, L. A., Jamar, D. C., Cueff, G., Rajjou, L., Hilhorst, H. W., Bentsink, L. (2016): The Arabidopsis DELAY OF GERMINATION 1 gene affects ABSCISIC ACID INSENSITIVE 5 (ABI5) expression and genetically interacts with ABI3 during Arabidopsis seed development. - Plant J. 85: 451-465.

[35] Derkx, M. P., Karssen, C. M. (1993): Effects of light and temperature on seed dormancy and gibberellin-stimulated germination in Arabidopsis thaliana: studies with gibberellindeficient and -insensitive mutants. - Physiol. Plant. 89: 360-368.

[36] Dill, A., Thomas, S. G., Hu, J., Steber, C. M., Sun, T. P. (2004): The Arabidopsis F-box protein SLEEPY1 targets gibberellin signaling repressors for gibberellin-induced degradation. - Plant Cell 16: 1392-1405. 
[37] Ding, L., Wang, Y., Yu, H. (2013): Overexpression of DOSOC1, an ortholog of Arabidopsis SOC1, promotes flowering in the orchid Dendrobium Chao Parya Smile. Plant Cell Physiol. 54: 595-608.

[38] Finch-Savage, W. E., Leubner-Metzger, G. (2006): Seed dormancy and the control of germination. - New Phytol. 171: 501-523.

[39] Finch-Savage, W. E., Cadman, C. S., Toorop, P. E., Lynn, J. R., Hilhorst, H. W. (2007): Seed dormancy release in Arabidopsis Cvi by dry after-ripening, low temperature, nitrate and light shows common quantitative patterns of gene expression directed by environmentally specific sensing. - Plant J. 51: 60-78.

[40] Finkelstein, R. (2013): Abscisic acid synthesis and response. - Arabidopsis Book 11: e0166.

[41] Finkelstein, R. R., Gampala, S. S., Rock, C. D. (2002): ABA signaling in seeds and seedlings. - Plant Cell 14: S15-S45.

[42] Finkelstein, R., Reeves, W., Ariizumi, T., Steber, C. (2008): Molecular aspects of seed dormancy. - Annu. Rev. Plant Biol. 59: 387-415.

[43] Fleet, C. M., Sun, T. P. (2005): A DELLAcate balance: the role of gibberellin in plant morphogenesis. - Curr. Opin. Plant Biol. 8: 77-85.

[44] Footitt, S., Douterelo-Soler, I., Clay, H., Finch-Savage, W. E. (2011): Dormancy cycling in Arabidopsis seeds is controlled by seasonally distinct hormone-signaling pathways. Proc. Natl. Acad. Sci. USA 108: 20236-20241.

[45] Foyer, C. H., Kerchev, P. I., Hancock, R. D. (2012): The ABA-INSENSITIVE-4 (ABI4) transcription factor links redox, hormone and sugar signaling pathways. - Plant Signal. Behav. 7: 276-281.

[46] Frey, A., Effroy, D., Lefebvre, V., Seo, M., Perreau, F., Berger, A., Sechet, J., To, A., North, H. M., Marion-Poll, A. (2011): Epoxycarotenoid cleavage by NCED5 fine-tunes ABA accumulation and affects seed dormancy and drought tolerance with other NCED family members. - Plant J. 70: 501-512.

[47] Fu, X., Richards, D. E., Fleck, B., Xie, D., Burton, N., Harberd, N. P. (2004): The Arabidopsis mutant sleepy1gar2-1 protein promotes plant growth by increasing the affinity of the SCFSLY1 E3 ubiquitin ligase for DELLA protein substrates. - Plant Cell 16: 14061418.

[48] Galvão, V. C., Horrer, D., Küttner, F., Schmid, M. (2012): Spatial control of flowering by DELLA proteins in Arabidopsis thaliana. - Development 139: 4072-4082.

[49] Gao, X. H., Xiao, S. L., Yao, Q. F., Wang, Y. J., Fu, X. D. (2011): An updated GA signaling 'relief of repression' regulatory model. - Mol. Plant 4: 601-606.

[50] Gong, X., Shen, L., Peng, Y. Z., Gan, Y., Yu, H. (2017): DNA topoisomerase Ialpha affects the floral transition. - Plant Physiol. 173: 642-654.

[51] Gosti, F., Beaudoin, N., Serizet, C., Webb, A. A., Vartanian, N., Giraudat, J. (1999): ABI1 protein phosphatase $2 \mathrm{C}$ is a negative regulator of abscisic acid signaling. - Plant Cell 11: 1897-1909.

[52] Graeber, K., Linkies, A., Müller, K., Wunchova, A., Rott, A., Leubner-Metzger, G. (2010): Cross-species approaches to seed dormancy and germination: conservation and biodiversity of ABA-regulated mechanism and the Brassicaceae DOG1 gene. - Plant Mol. Biol. 73: 67-87.

[53] Graeber, K., Voegele, A., Büttner-Mainik, A., Sperber, K., Mummenhoff, K., LeubnerMetzger, G. (2013): Spatiotemporal seed development analysis provides insight into primary dormancy induction and evolution of the Lepidium DELAY OF GERMINATION1 genes. - Plant Physiol. 161: 1903-1917.

[54] Graeber, K., Linkies, A., Steinbrecher, T., Mummenhoff, K., Tarkowská, D., Turečková, V., Ignatz, M., Sperber, K., Voegele, A., De Jong, H., Urbanová, T., Strnad, M., LeubnerMetzger, G. (2014): DELAY OF GERMINATION 1 mediates a conserved coat-dormancy mechanism for the temperature- and gibberellin-dependent control of seed germination. Proc. Natl. Acad. Sci. USA 111: E3571-E3580. 
[55] Grappin, P., Bouinot, D., Sotta, B., Miginiac, E., Jullien, M. (2000): Control of seed dormancy in Nicotiana plumbaginifolia: post-imbibition abscisic acid synthesis imposes dormancy maintenance. - Planta 210: 279-285.

[56] Griffiths, J., Murase, K., Rieu, I., Zentella, R., Zhang, Z. L., Powers, S. J., Gong, F., Phillips, A. L., Hedden, P., Sun, T. P., Thomas, S. G. (2006): Genetic characterization and functional analysis of the GID1 gibberellin receptors in Arabidopsis. - Plant Cell 18: 33993414.

[57] Groot, S. P., Karssen, C. M. (1992): Dormancy and germination of abscisic acid-deficient tomato seeds studies with the sitiens mutant. - Plant Physiol. 99: 952-958.

[58] Gubler, F., Hughes, T., Waterhouse, P., Jacobsen, J. (2008): Regulation of dormancy in barley by blue light and after-ripening: effects on abscisic acid and gibberellin metabolism. - Plant Physiol. 147: 886-896.

[59] Harberd, N. P. (2003): Relieving DELLA restraint. - Science 299: 1853-1854.

[60] Harberd, N. P., Belfield, E., Yasumura, Y. (2009): The angiosperm gibberellin-GID1DELLA growth regulatory mechanism: how an "inhibitor of an inhibitor" enables flexible response to fluctuating environments. - Plant Cell 21: 1328-1339.

[61] Holdsworth, M. J., Bentsink, L., Soppe, W. J. (2008): Molecular networks regulating Arabidopsis seed maturation, after-ripening, dormancy and germination. - New Phytol. 179: 33-54.

[62] Huijser, P., Schmid, M. (2011): The control of developmental phase transitions in plants. - Development 138: 4117-4129.

[63] Huo, H., Wei, S., Bradford, K. J. (2016): DELAY OF GERMINATION1 (DOG1) regulates both seed dormancy and flowering time through microRNA pathways. - Proc. Natl. Acad. Sci. USA 113: E2199-E2206.

[64] Hyun, Y., Richter, R., Vincent, C., Martinez-Gallegos, R., Porri, A., Coupland, G. (2016): Multi-layered regulation of SPL15 and cooperation with SOC1 integrate endogenous flowering pathways at the Arabidopsis shoot meristem. - Dev. Cell 37: 254-266.

[65] Iuchi, S., Suzuki, H., Kim, Y. C., Iuchi, A., Kuromori, T., Ueguchi-Tanaka, M., Asami, T., Yamaguchi, I., Matsuoka, M., Kobayashi, M., Nakajima, M. (2007): Multiple loss-offunction of Arabidopsis gibberellin receptor AtGID1s completely shuts down a gibberellin signal. - Plant J. 50: 958-966.

[66] Izydorczyk, C., Nguyen, T. N., Jo, S., Son, S., Tuan, P. A., Ayele, B. T. (2017): Spatiotemporal modulation of abscisic acid and gibberellin metabolism and signaling mediates the effects of suboptimal and supraoptimal temperatures on seed germination in wheat (Triticum aestivum L.). - Plant Cell Environ. 41: 1022-1037.

[67] Karssen, C. M., Lacka, E. (1986): A revision of the hormone balance theory of seed dormancy. - In: Bopp, M. (ed.) Plant growth substances. Springer-Verlag, Berlin, pp. 315323.

[68] Kendall, S. L., Hellwege, A., Marriot, P., Whalley, C., Graham, I. A., Penfield, S. (2011): Induction of dormancy in Arabidopsis summer annuals requires parallel regulation of DOG1 and hormone metabolism by low temperature and CBF transcription factors. - Plant Cell 23: 2568-2580.

[69] King, K. E., Moritz, T., Harberd, N. P. (2001): Gibberellins are not required for normal stem growth in Arabidopsis thaliana in the absence of GAI and RGA. - Genetics 159: 767776.

[70] Koops, P., Pelser, S., Ignatz, M., Klose, C., Marrocco-Selden, K., Kretsch, T. (2011): EDL3 is an F-box protein involved in the regulation of abscisic acid signalling in Arabidopsis thaliana. - J. Exp. Bot. 62: 5547-5560.

[71] Koornneef, M., Van der Veen, J. H. (1980): Induction and analysis of gibberellin-sensitive mutants in Arabidopsis thaliana (L) Heynh. - Theor. Appl. Genet. 58: 257-263.

[72] Koornneef, M., Reuling, G., Karssen, C. M. (1984): The isolation and characterization of abscisic acid insensitive mutants of Arabidopsis thaliana. - Physiol. Plant. 61: 377-383. 


$$
\text { - } 4716 \text { - }
$$

[73] Koornneef, M., Eigersma, A., Hanhart, C. J., Van loenen-Martinet, E. P., Van Rijn, L., Zeevaart, J. A. (1985): A gibberellin insensitive mutant of Arabidopsis thaliana. - Physiol. Plant. 65: 33-39.

[74] Koornneef, M., Bosma, T. D., Hanhart, C. J., Van der Veen, J. H., Zeevaart, J. A. (1990): The isolation and characterization of gibberellin-deficient mutants in tomato. - Theor. Appl. Genet. 80: 852-857.

[75] Kurup, S., Jones, H. D., Holdsworth, M. J. (2000): Interactions of the developmental regulator $\mathrm{ABI} 3$ with proteins identified from developing Arabidopsis seeds. - Plant J. 21: 143-155.

[76] Kushiro, T., Okamoto, M., Nakabayashi, K., Yamagishi, K., Kitamura, S., Asami, T., Hirai, N., Koshiba, T., Kamiya, Y., Nambara, E. (2004): The Arabidopsis cytochrome P450 CYP707A encodes ABA 8'-hydroxylases: key enzymes in ABA catabolism. - EMBO J. 23: 1647-1656.

[77] Lee, H. G., Lee, K., Seo, P. J. (2015): The Arabidopsis MYB96 transcription factor plays a role in seed dormancy. - Plant Mol. Biol. 87: 371-381.

[78] Li, M., An, F., Li, W., Ma, M., Feng, Y., Zhang, X., Guo, H. (2016): DELLA proteins interact with FLC to repress flowering transition. - J. Integr. Plant Biol. 58: 642-655.

[79] Li, X. Y., Chen, T. T., Li, Y., Wang, Z., Cao, H., Chen, F. Y., Li, Y., Soppe, W. J., Li, W. L., Liu, Y. X. (2019): ETR1/RDO3 regulates seed dormancy by relieving the inhibitory effect of the ERF12-TPL complex on DELAY OF GERMINATION 1 expression. - Plant Cell 31: 832-847.

[80] Ma, Y., Szostkiewicz, I., Korte, A., Moes, D., Yang, Y., Christmann, A., Grill, E. (2009): Regulators of PP2C phosphatase activity function as abscisic acid sensors. - Science 324: 1064-1068.

[81] Martinez-Andujar, C., Ordiz, M. I., Huang, Z., Nonogaki, M., Beachy, R. N., Nonogaki, H. (2011): Induction of 9-cis-epoxycarotenoid dioxygenase in Arabidopsis thaliana seeds enhances seed dormancy. - Proc. Natl. Acad. Sci. USA 108: 17225-17229.

[82] Matakiadis, T., Alboresi, A., Jikumaru, Y., Tatematsu, K., Pichon, O., Renou, J. P., Kamiya, Y., Nambara, E., Truong, H. N. (2009): The Arabidopsis abscisic acid catabolic gene CYP707A2 plays a key role in nitrate control of seed dormancy. - Plant Physiol. 149: 949-960.

[83] Murase, K., Hirano, Y., Sun, T. P., Hakoshima, T. (2008): Gibberellin-induced DELLA recognition by the gibberellin receptor GID1. - Nature 456: 459-463.

[84] Nakabayashi, K., Bartsch, M., Xiang, Y., Miatton, E., Pellengahr, S., Yano, R., Seo, M., Soppe, W. J. (2012): The time required for dormancy release in Arabidopsis is determined by DELAY OF GERMINATION1 protein levels in freshly harvested seeds. - Plant Cell 24: $2826-2838$.

[85] Nakajima, M., Shimada, A., Takashi, Y., Kim, Y. C., Park, S. H., Ueguchi-Tanaka, M., Suzuki, H., Katoh, E., Iuchi, S., Kobayashi, M., Maeda, T., Matsuoka, M., Yamaguchi, I. (2006): Identification and characterization of Arabidopsis gibberellin receptors. - Plant J. 46: 880-889.

[86] Nakashima, K., Fujita, Y., Kanamori, N., Katagiri, T., Umezawa, T., Kidokoro, S., Maruyama, K., Yoshida, T., Ishiyama, K., Kobayashi, M., Shinozaki, K., YamaguchiShinozaki, K. (2009): Three Arabidopsis SnRK2 protein kinases, SRK2D/SnRK2.2, SRK2E/SnRK2.6/OST1 and SRK2I/SnRK2.3, involved in ABA signaling are essential for the control of seed development and dormancy. - Plant Cell Physiol. 50: 1345-1363.

[87] Nambara, E., Marion-Poll, A. (2005): Abscisic acid biosynthesis and catabolism. - Annu. Rev. Plant Biol. 56: 165-185.

[88] Nambara, E., Okamoto, M., Tatematsu, K., Yano, R., Seo, M., Kamiya, Y. (2010): Abscisic acid and the control of seed dormancy and germination. - Seed Sci. Res. 20: 55-67.

[89] Née, G., Kramer, K., Nakabayashi, K., Yuan, B., Xiang, Y., Miatton, E., Finkemeier, I., Soppe, W. J. (2017a): DELAY OF GERMINATION1 requires PP2C phosphatases of the ABA signalling pathway to control seed dormancy. - Nat. Commun. 8: 72. 
[90] Née, G., Xiang, Y., Soppe, W. J. (2017b): The release of dormancy, a wake-up call for seeds to germinate. - Curr. Opin. Plant Biol. 35: 8-14.

[91] Ng, L. M., Melcher, K., Teh, B. T., Xu, H. E. (2014): Abscisic acid perception and signaling: structural mechanisms and applications. - Acta Pharmacol. Sin. 35: 567-584.

[92] Nishimura, N., Tsuchiya, W., Moresco, J. J., Hayashi, Y., Satoh, K., Kaiwa, N., Irisa, T., Kinoshita, T., Schroeder, J. I., Yates, J. R., Hirayama, T., Yamazaki, T. (2018): Control of seed dormancy and germination by DOG1-AHG1 PP2C phosphatase complex via binding to heme. - Nat. Commun. 9: 2132.

[93] Nonogaki, M., Sall, K., Nambara, E., Nonogaki, H. (2014): Amplification of ABA biosynthesis and signaling through a positive feedback mechanism in seeds. - Plant J. 78: 527-539.

[94] North, H., Baud, S., Debeaujon, I., Dubos, C., Dubreucq, B., Grappin, P., Jullien, M., Lepiniec, L., Marion-Poll, A., Miquel, M., Rajjou, L., Routaboul, J. M., Caboche, M. (2010): Arabidopsis seed secrets unravelled after a decade of genetic and omics-driven research. - Plant J. 61: 971-981.

[95] Park, S. Y., Fung, P., Nishimura, N., Jensen, D. R., Fujii, H., Zhao, Y., Lumba, S., Santiago, J., Rodrigues, A., Chow, T. F., Alfred, S. E., Bonetta, D., Finkelstein, R., Provart, N. J., Desveaux, D., Rodriguez, P. L., McCourt, P., Zhu, J. K., Schroeder, J. I., Volkman, B. F., Cutler, S. R. (2009): Abscisic acid inhibits type 2 C protein phosphatases via the PYR/PYL family of START proteins. - Science 324: 1068-1071.

[96] Park, J., Oh, D. H., Dassanayake, M., Nguyen, K. T., Ogas, J., Choi, G., Sun, T. P. (2017): Gibberellin signaling requires chromatin remodeler PICKLE to promote vegetative growth and phase transitions. - Plant Physiol. 173: 1463-1474.

[97] Porri, A., Torti, S., Romera-Branchat, M., Coupland, G. (2012): Spatially distinct regulatory roles for gibberellins in the promotion of flowering of Arabidopsis under long photoperiods. - Development 139: 2198-2209.

[98] Post, E. S., Pedersen, C., Wilmers, C. C., Forchhammer, M. C. (2008): Phenological sequences reveal aggregate life-history response to climatic warming. - Ecology 89: 363370.

[99] Riboni, M., Galbiati, M., Tonelli, C., Conti, L. (2013): GIGANTEA enables drought escape response via abscisic acid-dependent activation of the florigens and SUPPRESSOR OF OVEREXPRESSION OF CONSTANS1. - Plant Physiol. 162: 1706-1719.

[100] Riboni, M., Test, A. R., Galbiati, M., Tonelli, C., Conti, L. (2016): ABA-dependent control of GIGANTEA signalling enables drought escape via up-regulation of FLOWERING LOCUS T in Arabidopsis thaliana. - J. Exp. Bot. 67: 6309-6322.

[101] Saito, S., Hirai, N., Matsumoto, C., Ohigashi, H., Ohta, D., Sakata, K., Mizutani, M. (2004): Arabidopsis CYP707As encode (+)-abscisic acid 8'-hydroxylase, a key enzyme in the oxidative catabolism of abscisic acid. - Plant Physiol. 134: 1439-1449.

[102] Salazar-Cerezo, S., Martínez-Montiel, N., García-Sánchez, J., Pérez-Y-Terrón, R., Martínez-Contreras, R. D. (2018): Gibberellin biosynthesis and metabolism: A convergent route for plants, fungi and bacteria. - Microbiol. Res. 208: 85-98.

[103] Sawettalake, N., Bunnag, S., Wang, Y., Shen, L., Yu, H. (2017): DOAP1 promotes flowering in the orchid Dendrobium Chao Praya Smile. - Front. Plant Sci. 8: 400.

[104] Schwartz, S. H., Qin, X., Zeevaart, J. A. (2003): Elucidation of the indirect pathway of abscisic acid biosynthesis by mutants, genes, and enzymes. - Plant Physiol. 131: 15911601.

[105] Seo, M., Hanada, A., Kuwahara, A., Endo, A., Okamoto, M., Yamauchi, Y., North, H., Marion-Poll, A., Sun, T. P., Koshiba, T., Kamiya, Y., Yamaguchi, S., Nambara, E. (2006): Regulation of hormone metabolism in Arabidopsis seeds: phytochrome regulation of abscisic acid metabolism and abscisic acid regulation of gibberellin metabolism. - Plant J. 48: 354-366.

[106] Seo, M., Nambara, E., Choi, G., Yamaguchi, S. (2009): Interaction of light and hormone signals in germinating seeds. - Plant Mol. Biol. 69: 463-472. 
[107] Shu, K., Zhang, H., Wang, S., Chen, M., Wu, Y., Tang, S., Liu, C., Feng, Y., Cao, X., Xie, Q. (2013): ABI4 regulates primary seed dormancy by regulating the biogenesis of abscisic acid and gibberellins in Arabidopsis. - PLoS Genet. 9: e1003577.

[108] Shu, K., Chen, Q., Wu, Y., Liu, R., Zhang, H., Wang, S., Tang, S., Yang, W., Xie, Q. (2016a): ABSCISIC ACID-INSENSITIVE 4 negatively regulates flowering through directly promoting Arabidopsis FLOWERING LOCUS C transcription. - J. Exp. Bot. 67: 195-205.

[109] Shu, K., Liu, X. D., Xie, Q., He, Z. H. (2016b): Two Faces of One Seed: Hormonal Regulation of Dormancy and Germination. - Mol. Plant 9: 34-45.

[110] Shu, K., Zhou, W. G., Yang, W. Y. (2017): APETALA 2-domain-containing transcription factors: focusing on abscisic acid and gibberellins antagonism. - New Phytol. 217: 977983.

[111] Shu, K., Luo, X. F., Meng, Y. J., Yang, W. Y. (2018a): Toward a molecular understanding of abscisic acid actions in floral transition. - Plant Cell Physiol. 59: 215-221.

[112] Shu, K., Zhou, W. G., Chen, F., Luo, X. F., Yang, W. Y. (2018b): Abscisic Acid and Gibberellins Antagonistically Mediate Plant Development and Abiotic Stress Responses. Front. Plant Sci. 9: 416.

[113] Silverstone, A. L., Jung, H. S., Dill, A., Kawaide, H., Kamiya, Y., Sun, T. P. (2001): Repressing a repressor: gibberellin-induced rapid reduction of the RGA protein in Arabidopsis. - Plant Cell 13: 1555-1566.

[114] Söderman, E. M., Brocard, I. M., Lynch, T. J., Finkelstein, R. R. (2000): Regulation and function of the Arabidopsis ABA-insensitive4 gene in seed and abscisic acid response signaling networks. - Plant Physiol. 124: 1752-1765.

[115] Spanudakis, E., Jackson, S. (2014): The role of microRNAs in the control of flowering time. - J. Exp. Bot. 65: 365-380.

[116] Springthorpe, V., Penfield, S. (2015): Flowering time and seed dormancy control use external coincidence to generate life history strategy. - eLife 4: e05557.

[117] Srikanth, A., Schmid, M. (2011): Regulation of flowering time: all roads lead to Rome. Cell. Mol. Life Sci. 68: 2013-2037.

[118] Sugimoto, K., Takeuchi, Y., Ebana, K., Miyao, A., Hirochika, H., Hara, N., Ishiyama, K., Kobayashi, M., Ban, Y., Hattori, T., Yano, M. (2010): Molecular cloning of Sdr4, a regulator involved in seed dormancy and domestication of rice. - Proc. Natl. Acad. Sci. USA 107: 5792-5797.

[119] Sun, T., Kamiya, Y. (1994): The Arabidopsis GA1 locus encodes the cyclase ent-kaurene synthetase A of gibberellin biosynthesis. - Plant Cell 6: 1509-1518.

[120] Thompson, A. J., Jackson, A. C., Symonds, R. C., Mulholland, B. J., Dadswell, A. R., Blake, P. S., Burbidge, A., Taylor, I. B. (2000): Ectopic expression of a tomato 9-cisepoxycarotenoid dioxygenase gene causes over-production of abscisic acid. - Plant J. 23: 363-374.

[121] Tiwari, S. B., Shen, Y., Chang, H. C., Hou, Y., Harris, A., Ma, S. F., McPartland, M., Hymus, G. J., Adam, L., Marion, C., Belachew, A., Repetti, P. P., Reuber, T. L., Ratcliffe, O. J. (2010): The flowering time regulator CONSTANS is recruited to the FLOWERING LOCUS T promoter via a unique cis-element. - New Phytol. 187: 57-66.

[122] Tuan, P. A., Kumar, R., Rehal, P. K., Toora, P. K., Ayele, B. T. (2018): Molecular Mechanisms Underlying Abscisic Acid/Gibberellin Balance in the Control of Seed Dormancy and Germination in Cereals. - Front. Plant Sci. 9: 668.

[123] Tuttle, K. M., Martinez, S. A., Schramm, E. C., Takebayashi, Y., Seo, M., Steber, C. M. (2015): Grain dormancy loss is associated with changes in ABA and GA sensitivity and hormone accumulation in bread wheat, Triticum aestivum (L.). - Seed Sci. Res. 25: 179193.

[124] Vaistij, F. E., Gan, Y., Penfield, S., Gilday, A. D., Dave, A., He, Z., Josse, E. M., Choi, G., Halliday, K. J., Graham, I. A. (2013): Differential control of seed primary dormancy in 
Arabidopsis ecotypes by the transcription factor SPATULA. - Proc. Natl. Acad. Sci. USA 110: 10866-10871.

[125] Vishwakarma, K., Upadhyay, N., Kumar, N., Yadav, G., Singh, J., Mishra, R. K., Kumar, V., Verma, R., Upadhyay, R. G., Pandey, M., Sharma, S. (2017): Abscisic Acid Signaling and Abiotic Stress Tolerance in Plants: A Review on Current Knowledge and Future Prospects. - Front. Plant Sci. 8: 161.

[126] Wallner, E. S., López-Salmerón, V., Greb, T. (2016): Strigolactone versus gibberellin signaling: reemerging concepts. - Planta 243: 1339-1350.

[127] Wang, J. W., Czech, B., Weigel, D. (2009): miR156-regulated SPL transcription factors define an endogenous flowering pathway in Arabidopsis thaliana. - Cell 138: 738-749.

[128] Wang, Y., Li, L., Ye, T., Lu, Y., Chen, X., Wu, Y. (2013): The inhibitory effect of ABA on floral transition is mediated by ABI5 in Arabidopsis. - J. Exp. Bot. 64: 675-684.

[129] Willige, B. C., Ghosh, S., Nill, C., Zourelidou, M., Dohmann, E. M. N., Maier, A., Schwechheimer, C. (2007): The DELLA domain of GA INSENSITIVE mediates the interaction with the GA INSENSITIVE DWARF1A gibberellin receptor of Arabidopsis. Plant Cell 19: 1209-1220.

[130] Wilson, R. N., Heckman, J. W., Somerville, C. R. (1992): Gibberellin is required for flowering in Arabidopsis thaliana under short days. - Plant Physiol. 100: 403-408.

[131] Wu, G., Park, M. Y., Conway, S. R., Wang, J. W., Weigel, D., Poethig, R. S. (2009): The sequential action of miR156 and miR172 regulates developmental timing in Arabidopsis. - Cell 138: 750-759.

[132] Yamaguchi, S., Kamiya, Y. (2002): Gibberellins and light-stimulated seed germination. J. Plant Growth Regul. 20: 369-376.

[133] Yamaguchi, S. (2006): Gibberellin biosynthesis in Arabidopsis. - Phytochem. Rev. 5: 3947.

[134] Yamaguchi, S. (2008): Gibberellin metabolism and its regulation. - Annu. Rev. Plant Biol. 59: 225-251.

[135] Yamaguchi, A., Abe, M. (2012): Regulation of reproductive development by non-coding RNA in Arabidopsis: to flower or not to flower. - J. Plant Res. 125: 693-704.

[136] Yamauchi, Y., Ogawa, M., Kuwahara, A., Hanada, A., Kamiya, Y., Yamaguchi, S. (2004): Activation of gibberellin biosynthesis and response pathways by low temperature during imbibition of Arabidopsis thaliana seeds. - Plant Cell 16: 367-378.

[137] Yang, W., Zhang, W., Wang, X. (2017): Post-translational control of ABA signalling: the roles of protein phosphorylation and ubiquitination. - Plant Biotechnol. J. 15: 4-14.

[138] Yoshida, T., Fujita, Y., Maruyama, K., Mogami, J., Todaka, D., Shinozaki, K., YamaguchiShinozaki, K. (2014): Four Arabidopsis AREB/ABF transcription factors function predominantly in gene expression downstream of SnRK2 kinases in abscisic acid signalling in response to osmotic stress. - Plant Cell Environ. 38: 35-49.

[139] Yoshida, T., Mogami, J., Yamaguchi-Shinozaki, K. (2015): Omics Approaches Toward Defining the Comprehensive Abscisic Acid Signaling Network in Plants. - Plant Cell Physiol. 56: 1043-1052.

[140] Yu, S., Galvão, V. C., Zhang, Y. C., Horrer, D., Zhang, T. Q., Hao, Y. H., Feng, Y. Q., Wang, S., Schmid, M., Wang, J. W. (2012): Gibberellin regulates the Arabidopsis floral transition through miR156-targeted SQUAMOSA PROMOTER BINDING-LIKE transcription factors. - Plant Cell 24: 3320-3332.

[141] Yu, F., Wu, Y., Xie, Q. (2015): Precise protein post-translational modifications modulate ABI5 activity. - Trends Plant Sci. 20: 569-575.

[142] Zhang, X., Garreton, V., Chua, N. H. (2005): The AIP2 E3 ligase acts as a novel negative regulator of $\mathrm{ABA}$ signaling by promoting $\mathrm{ABI} 3$ degradation. - Genes Dev. 19: 1532-1543.

[143] Zhang, H., Rider, S. D., Henderson, J. T., Fountain, M., Chuang, K., Kandachar, V., Simons, A., Edenberg, H. J., Romero-Severson, J., Muir, W. M., Ogas, J. (2008): The CHD3 remodeler PICKLE promotes trimethylation of histone H3 lysine 27. - J. Biol. Chem. 283: 22637-22648. 
[144] Zhang, D., Jing, Y., Jiang, Z., Lin, R. (2014): The chromatin-remodeling factor PICKLE integrates brassinosteroid and gibberellin signaling during skotomorphogenic growth in Arabidopsis. - Plant Cell 26: 2472-2485.

[145] Zhao, M., Yang, S., Liu, X., Wu, K. (2015): Arabidopsis histone demethylases LDL1 and LDL2 control primary seed dormancy by regulating DELAY OF GERMINATION 1 and ABA signaling-related genes. - Front. Plant Sci. 6: 159.

[146] Zhu, Q. H., Helliwell, C. A. (2011): Regulation of flowering time and floral patterning by miR172. - J. Exp. Bot. 62: 487-495.

[147] Zhu, Y., Liu, L., Shen, L., Yu, H. (2016): NaKR1 regulates long-distance movement of FLOWERING LOCUS T in Arabidopsis. - Nat. Plants 2: 16075. 